\title{
Self-Reliance Requires Government Funding for Basic and Applied Scientific Research with Active Participation by Industries
}

The editorial by Lakhotia, Editor-in-chief of the Proceedings of Indian National Science Academy in the December 2015 issue is thought provoking and timely. Can the government expect industries to take on funding for scientific research? Profit making is an important objective of all industries. They look for quick-fix solutions that help manufacturing. These invariably involve importing readily available technologies and know-hows from developed countries and at best do retro-fitting. Developed countries invest in products for which there is demand in their country. For instance in the area of drugs, pharma industries in developed countries would rather invest in development of drugs for degenerative diseases like cardiovascular diseases, cancer, neurological disorders etc. than in drugs for infectious disease like tuberculosis, malaria etc. which are problems of developing countries. India has to have strong R\&D capability to address health related and other needs of India. Growing problem of drug resistance to infectious diseases, demands out of box thinking and innovation to check-mate the bugs that are proving to be smarter than humans.

India needs a blend of basic, directed basic and applied research, and human resource to support it. Open- sky basic research does not have quick answers which can start spinning money. Yet, if India has to develop with self-reliance, it has to invest in basic research. While the government has to play a major role, industries can be motivated to contribute generously to basic research under their Corporate Social Responsibility. It would be nice if a common pool of funding from different money-making industries can be generated for basic and directed basic research, with no strings attached.

The points made in the editorial about science teaching are important. India needs good science teachers who can inspire students. Some effort in that direction is being made by organizations like Jana Vignana Vedika (Andhra Pradesh and Telangana) which are part of people's science movement by organizing workshops for science teachers, including those from rural schools. Government and academy programmes like INSPIRE are a step in the right direction. Science teaching should kindle curiosity and not be rote. As it is our exams assess children's memory rather than their knowledge or ability to think. 